\title{
Influence of the Grander Technology in the Physical Properties of the Self-Etch Adhesive System
}

\author{
Sérgio Eduardo de Paiva Gonçalves, Diogo Toledo Matias, Daphne Câmara Barcellos \\ Maria Filomena Rocha Lima Huhtala, Tânia Mara da Silva, Ivan Balducci, Carlos Rocha Gomes Torres
}

\section{ABSTRACT}

Aim: The objective of this study was to evaluate the influence of the Grander technology in reducing the surface tension and contact angle of self-etch adhesive system.

Materials and methods: Distilled water and Xeno III self-etch adhesive system (Dentsply) were modified by physical contact with the flexible unit Grander system to revitalize water, for 48 hours, resulting in four groups: Group CW-distilled water under normal conditions; Group CA-Xeno III adhesive system under normal conditions; Group GW-distilled water system modified by the Grander system; Group GA-Xeno III adhesive system modified by the Grander system. Surface tension and contact angle of the adhesive system and water in normal and Grandermodified conditions was measured with a goniometer. ANOVA and Tukey test were used to analyze the results (5\%).

Results and conclusion: For surface tension, ANOVA showed $p<0.05$, what indicated significant differences between the groups. The mean values $(\mathrm{D} / \mathrm{cm})$ for the groups were: $\mathrm{CW}-72.4$ a; GW-69.45 b; GA: 31.17 c; CA-29.98 c. The results showed a significant reduction of surface tension for distilled water modified by Grander system. Grander technology did not interfere in the surface tension and contact angle physical properties of the Xeno III self-etch adhesive system.

Clinical significance: Grander technology is a method that revitalizes water by physical spatial restructuring of its molecules. The modify of an adhesive system, also a liquid with an aqueous solvent, can provide a reduction in surface tension and contact angle, increasing its wetness capacity and therefore ensuring a greater diffusibility.

Keywords: Grander technology, Surface tension, Contact angle, Self-etch adhesive systems.

How to cite this article: de Paiva Gonçalves SE, Matias DT, Barcellos DC, Lima Huhtala MFR, da Silva TM, Balducci I, Torres CRG. Influence of the Grander Technology in the Physical Properties of the Self-Etch Adhesive System. World J Dent 2012;3(1):1-5.

\section{Source of support: Nil}

Conflict of interest: None declared

\section{INTRODUCTION}

The use of adhesive systems in Dentistry was initiated when Buonocore $(1955)^{1}$ developed the technique of etching enamel. This technique is based on etching enamel surface with phosphoric acid gel, at a concentration between 30 and $40 \%$, which promotes the selective dissolution of hydroxyapatite crystals, producing surface microporosity and increased surface energy of enamel. ${ }^{2}$
This etching provides a superficial layer removal of enamel around $10 \mu \mathrm{m}$, creating a porous layer of 5 to $10 \mu \mathrm{m}$. $^{3}$ The mechanism of bonding adhesive to enamel is explained by the increase surface energy of the enamel from 28 to 72 dynes $/ \mathrm{cm}^{4}$ after etching, by the creation of microporosity restraint geometry, which is subsequently filled by the adhesive, forming the $\operatorname{tags} .^{5}$ The low viscosity of the adhesives allows the flow in these micropores by capillary action, providing a micromechanical union after its cure. ${ }^{6}$

To obtain an adequate bond between the enamel substrate and adhesive system, it is necessary the formation of a small contact angle of the adhesive deposited on the enamel, what shows a good moistening capacity of the surface by the adhesive. ${ }^{7,8}$ The ideal interaction occurs when the surface tension of the adhesive system is slightly lower than the surface energy of the substrate. ${ }^{9-11}$

Following the modern trend of simplifying the clinical steps and saving operating time, new bonding strategies were developed. Watanabe in $1994,{ }^{13}$ proposed the use of high concentrations of acidic resinous monomers which, in an aqueous solution, are capable of releasing $\mathrm{H}^{+}$ions and producing etching of the dental structure, at the same time as they penetrate into the substrate. ${ }^{12}$ These materials were called self-etching, since they dispensed the separate application of the acid.

Although they presented good performance in dentin, ${ }^{14-16}$ some researchers have suggested that due to their low acidity, their performance in enamel is lower and capable of leading to low bond strength values in this substrate. ${ }^{16,17}$ Morphologic studies of enamel surfaces have demonstrated that the application of some self-etching primers does not result in the same etching when compared with that produced by phosphoric acid, ${ }^{16,17}$ and their use in regions with extensive areas of enamel is very controversial. ${ }^{15}$

Recently, Johan Grander developed the Grander technology, a method that revitalizes water by physical spatial restructuring of its molecules. This restructuring allows a molecular balance with improved transportation properties, ${ }^{18}$ probably by reducing its surface tension. ${ }^{19}$ By extrapolating the water revitalization process for the ideal conditions desired in terms of adhesiveness, we could modify an adhesive system, also a liquid with an aqueous solvent, to provide a reduction in surface tension and contact angle, increasing its wetness capacity and therefore ensuring a greater diffusibility. 
The objective of this study was to evaluate the influence of Grander technology in the surface tension and contact angle of self-etch adhesive system. The null hypothesis tested was that the Grander technology cannot change the surface tension and contact angle physical properties of the adhesive system.

\section{MATERIALS AND METHODS}

\section{Modification of Adhesive System and Water by the Grander System}

The first step required for the execution of the entire methodology was the modification of the Xeno III self-etch adhesive system (Dentsply De Trey GmbH D, Konstanz, Germany) and of the water by the Grander system:

- Experimental: Two sets of the same batch of the adhesive system were used. One set was kept unchanged and the other was placed in physical contact with the Grander system Flexible unit (Grander Technologies, Jochberg, Austria). This system consists of a device named Flexible unit, capable of revitalizing waters by electromagnetic induction of molecular rearrangement through contact with bottles of liquids or by the passage of liquids through the interior of channels placed among cylinders that build the core of the unit. Thus, the bottles of adhesive system were placed in contact with the unit flexible for 48 hours.

- Control: Two bottles with $5 \mathrm{ml}$ of distilled water were revitalized by the Grander system for 48 hours, following the same treatments described above.

The commercial name, chemical composition, batch number and manufacturer of the material used are presented in Table 1.

\section{Surface Tension Measurement}

For surface tension, four groups were established as follows:

- Group 1-Distilled water (control);

- Group 2-Grander-modified distilled water (experimental);
- Group 3-Xeno III self-etch adhesive system (control);

- Group 4-Grander-modified Xeno III self-etch adhesive system (experimental).

Surface tension of each group was measured by automatic goniometer (Ramé-Hart Instrument Co. 0.100-00, Washington DC, USA). Temperature and moisture conditions of the environment were controlled in $23^{\circ} \mathrm{C}$ and $50 \%$ respectively.

Samples were collected from each group on a microsyringe (Gilmont, Barrington, Illinois, USA). The microsyringe presents a micrometer Teflon, a glass barrel, a rubber sealing ring and a metallic needle number 22 . The barrel was wrapped in aluminum foil in order to prevent adhesive systems polymerization in its interior, due to the room light. The whole set was fixed in the goniometer support to measure the surface tension.

By turning the micrometer screw clockwise by hand, a gradual drop of liquid was obtained, which remained attached to the needle tip due to its surface tension. The device allows adjustment of the number of steps/time. Twenty measures were taken for every drop of each liquid tested, yielding an average of surface tension.

Data were submitted to the two-way ANOVA (liquid and procedure factors) followed by the Tukey test, at a 5\% level of significance.

\section{Contact Angle Measurement}

For contact angle measurement, two groups were established as follows:

- Group 1-Xeno III self-etch adhesive system (control);

- Group 2-Grander-modified Xeno III self-etch adhesive system (experimental).

The contact angle was evaluated in two different substrates: Titanium plate and enamel substrate.

- Contact angle measurement in the titanium plate: Ten drops of Xeno III adhesive system were dropped individually on a titanium plate. The waiting time of

Table 1: Commercial name, composition, batch number and manufacturer of the material used

\begin{tabular}{|c|c|c|c|}
\hline Commercial name & Composition & Batch number & Manufacturer \\
\hline $\begin{array}{l}\text { Xeno III self-etch } \\
\text { adhesive system }\end{array}$ & $\begin{array}{l}\text { Agent A: HEMA, ethanol, } \\
\text { amorphous silica, purified water, } \\
\text { and THB (toluene hydroxybutylate). } \\
\text { Agent B: Methacrylic } \\
\text { functionalized with phosphoric } \\
\text { acid (Piro-EMA); Monofluoro } \\
\text { phosphazene } \\
\text { modified (PEM-F) of urethane } \\
\text { dimethacrylate; THB; } \\
\text { Camphorquinone and } \\
\text { ethyl-4-dimethylamino-benzoate }\end{array}$ & 0605000261 & $\begin{array}{l}\text { Dentsply De Trey GmbH, Konstanz, } \\
\text { Germany }\end{array}$ \\
\hline
\end{tabular}


20 seconds was standardized to froze the image at the time that the drop contacted the surface of the titanium plate. The contact angle was measured by an automatic goniometer (Ramé-Hart Instrument Co. 0.100-00, Washington DC, USA). Temperature and moisture conditions of the environment were controlled in $23^{\circ} \mathrm{C}$ and $50 \%$ respectively. For each drop, twenty measurements were performed and the mean values were calculated. The titanium plate was used primarily because it is inert, therefore, the drop scattering is bound only to the properties of the liquid dripped, without influence of the substrate.

- Contact angle measurement in the enamel substrate: Forty extracted bovine incisors were cleaned and stored in distilled and deionized water in a freezer at $-18^{\circ} \mathrm{C}$ until the time of use. Then the roots were sectioned with a steel diamond disk (KG Sorensen, Rio de Janeiro, Brazil) at the cement-enamel junction. The buccal surfaces were worn using abrasive papers (granulations 400 and 600) coupled to a circular polishing machine (PA-10, Panambra, São Paulo, Brazil) under water cooling, to expose an area in enamel measuring a minimum of $4 \times 4 \mathrm{~mm}$. An opening was made on the lingual side using a spherical diamond tip 1012 (KG Sorensen, Rio de Janeiro, RJ, Brazil) to remove the pulpal tissue. The openings on the lingual face and root canal were clogged with utility wax (Polidental, Cotia, SP, Brazil). After this the worn buccal faces were turned facing down in a silicone mold, which was then filled with self-polymerizing acrylic resin (Classic, São Paulo, Brazil). The enamel surface was standardized using abrasive papers (granulations 1200 and 4000) for 20s each, coupled to a circular polishing machine. Each specimen received on the enamel surface one drop of Xeno III adhesive system, totalizing 20 drops for each group (experimental and control). The contact angle was measured by the same protocols described above. For each drop, 20 measurements were realized and the mean values were calculated.

For contact angle, data were submitted to the two-way ANOVA (substrate and procedure factors) followed by the Tukey test, at a 5\% level of significance.

\section{RESULTS}

\section{Surface Tension}

For liquid factor, ANOVA showed a p-value $=0.0001$ $(F=3240.63)$, with 1 degree of freedom. The ANOVA showed a $p$-value $=0.23(\mathrm{~F}=1.55)$, with 1 degree of freedom for procedure factor. The ANOVA showed a $\mathrm{p}$-value $=$ $0.0098(\mathrm{~F}=8.58)$, with 1 degree of freedom for interaction between factors. Liquid factor and interaction between liquid and procedure factors showed significant differences between groups.

Table 2 shows the results of Tukey's test for liquid factor. Distilled water showed surface tension reduced significantly compared to Xeno III adhesive system.

Table 3 shows the results of Tukey's test for interaction between factors. Distilled water modified by the Grander system (experimental group) showed surface tension reduced significantly compared to distilled water of the control group.

\section{Contact Angle}

For procedure factor, ANOVA showed a p-value $=0.1628$ $(\mathrm{F}=2.00)$, with 1 degree of freedom. The ANOVA showed a $\mathrm{p}$-value $=0.0514(\mathrm{~F}=3.96)$, with 1 degree of freedom for procedure factor. The ANOVA showed a $p$-value $=0.4797$ $(F=0.51)$, with 1 degree of freedom for interaction between factors. The results showed absence of the significant differences between groups.

\section{DISCUSSION}

The modification of an adhesive system by a physical process of molecular rearrangement, done either by the professional researcher or by the manufacturer, opens new possibilities for researches to the adhesion stability. By extrapolating the water revitalization process for the ideal

Table 2: Tukey's test results for procedure factor $(\mathrm{D} / \mathrm{cm})$

\begin{tabular}{llc}
\hline Liquid & Mean $(\mathrm{D} / \mathrm{cm})$ & Homogeneous sets* \\
\hline Distilled water & 70.931 & $\mathrm{~A}$ \\
Adhesive system & 30.580 & $\mathrm{~B}$ \\
\hline
\end{tabular}

* The groups accompanied by the same letters presented no significant differences

Table 3: Tukey's test results for interaction between the factors $(D / \mathrm{cm})$

\begin{tabular}{llcc}
\hline Procedure & Liquid & Mean $(\mathrm{D} / \mathrm{cm})$ & Homogeneous sets* $^{*}$ \\
\hline Control & Distilled water & 72.411 & $\mathrm{~A}$ \\
Grander-modified & Distilled water & 69.452 & $\mathrm{~B}$ \\
Grander-modified & Adhesive system & 31.177 & $\mathrm{C}$ \\
Control & Adhesive system & 29.984 & $\mathrm{C}$ \\
\hline
\end{tabular}

*The groups accompanied by the same letters presented no significant differences 
conditions in terms of adhesiveness, the modification of an adhesive system increasing its wetness capacity ensuring a greater diffusibility and, perhaps, its molecular stability is desire for dentistry. ${ }^{20}$

Gonçalves ${ }^{20}$ (2005) showed that the Grander technology affect the physical properties of Single Bond and Clearfil SE Bond adhesive systems, reducing surface tension and contact angle of these adhesive systems. Additionally, Gonçalves ${ }^{18}$ observed that both adhesive systems generated greater thickness hybrid layer and the Single Bond totaletch adhesive system created a greater thickness of the hybridization compared to Clearfil SE Bond self-etch adhesive system, regardless of the substrate and the procedure (control or Grander-modified).

This study showed that distilled water Grander-modified reduced significantly the surface tension when compared to distilled water control (procedure factor). These results are agreement with Gonçalves ${ }^{20}$ (2005), who noted a significant reduction in surface tension of water after revitalization process by Grander system. Corroborating our study, Faissner ${ }^{21}$ (2000) evaluated all properties of water after revitalization process (ionic balance, density, conductivity, $\mathrm{pH}$, surface tension, test with boiling alcohol and diagram) and he observed that surface tension showed the most significant change, around 10\%.

Also, this study observed that the Xeno III adhesive system showed lower surface tension compared to distilled water (liquid factor). However, the interaction between liquid and procedure factors showed absence of significance. The Xeno III adhesive system do not reduced significantly the surface tension after revitalization process by Grander system, probably because the percentage of water present in it is lower, or alternatively, this adhesive system present greater molecular complexity, differently to the results founded by Gonçalves ${ }^{20}$ (2005), who observed surface tension reduced significantly after revitalization process by Grander system of the Single Bond and Clearfil SE Bond adhesive systems. The reduced surface tension demonstrates a greater ability of the liquid to wet the substrate and, thereby, improve the adhesiveness and diffusibility. ${ }^{22}$

The Xeno III adhesive system contains water and ethanol as solvents in it composition. Theoretically, it should cause changes after revitalization process by Grander system. However, this did not occur, probably because water and ethanol in it formulation present small concentrations. Also, this adhesive system contains high viscosity due the presence of silica and urethane dimethacrylate. Our study do not observe visual change in viscosity of this adhesive system after revitalization process, contrasting with the findings by Gonçalves ${ }^{20}$ (2005), who found greater fluidity of the Single Bond and Clearfil SE Bond adhesive systems after revitalization process by Grander system.
With regard to contact angle, our results demonstrate absence of significant difference between procedure (control and Grander-modified) and substrate factors (enamel substrate and titanium plate). According to Won-suck et $\mathrm{al}^{23}$ (2002), the contact angle vary due surface topography, surface tension, surface energy of solid substrate and the level of interaction between the liquid and solid. Therefore, the smaller the contact angle, the greater the surface wettability. Thus, the contact angle values vary according to surface tension of liquid. The absence of significant reduction in surface tension generates absence of significant variation in the contact angle. This result is probably due to the physical and chemical characteristics of the Xeno III adhesive system.

The dental literature is scarce in studies about surface tension and contact angle of current adhesive systems. However, this study showed that distilled water was modified by Grander system after revitalization process, wherever, Xenno III adhesive system did not show the same results. Probably because it presents higher viscosity and more time in contact with the Grander unit for revitalization process is necessary. The Grander technology is a new technology, therefore, others studies are necessary to demonstrate the possible revitalization process by the Grande system in the adhesive systems.

\section{CONCLUSION}

Based on the methodology employed, it can be concluded that:

- Distilled water reduced the surface tension significantly revitalization process by Grander system compared to distilled water control;

- Grander technology do not interfere the surface tension and contact angle physical properties of the Xeno III self-etch adhesive system.

\section{REFERENCES}

1. Buonocore MG. A simple method of increasing the adhesion of acrylic filling materials to enamel surfaces. J Dent Res 1955;34(6):849-53.

2. Perdigão J, Ritter AV. Adhesion to dentinary tissues. In: Baratieri LN. Restorative Dentistry: Fundaments and Possibilities. São Paulo: Santos; 2001.

3. Silverstone LM. The acid-etch technique: In-vitro studies with special reference to the enamel surface and the enamel resin interface. Proc Int Symp Acid Etch Tech. St Paul: North Central Publishing; 1975.

4. Jendresen MD, Glantz PO. Clinical adhesiveness of selected dental materials. An in-vivo study. Acta Odontol Scand 1981;39(1):39-45.

5. Henostroza Haro G, Henostroza Quintans N. Adhesion in restorative dentistry. Latin american association of operative dentistry and biomaterials. Ripano: Spain; 2010.

6. Nakabayashi N, Pashley DH. Hybridization of dental hard tissues. Tokyo: Quintessence Publishing Co., 2000. 
7. Retief DH. Effect of conditioning the enamel surface with phosphoric acid. J Dent Res 1973;52(2):333-41.

8. Glantz PO. A clinical method for the study of in-vivo adhesiveness of teeth. Acta Odontol Scand 1980;38(6):371-78.

9. Uribe-Echevarría J. Operatoria Dental, Ciencia y Práctica. Ediciones Avances Medico-Dentales SL Madrid: Spain; 1990.

10. Schwartz Rs, Summitt Jb, Robbins JW. Fundamentals of operative dentistry: A contemporary approach. Chicago: Quintessence Pub. Co. 1996.

11. Blunck U. Adhesives: Principles and state of the art. In: Roulet JF, Degrange M. Adhesion: The silent revolution in dentistry. Carol Stream (IL): Quintessence Publishing, 2000.

12. Watanabe I, Nakabayashi N, Pashley DH. Bonding to ground dentin by Phenil-P self-etching primer. J Dent Res 1994;73(6):1212-20.

13. Ferrari M, Mannocci F, Vichi A, Davidson CL. Effect of two etching times on the sealing ability of 14-Clearfil Liner Bond 2 in Class V restorations. Am J Dent 1997;10(2):66-70.

14. Itou K, Torii Y, Takimura T, Chikami K, Ishikama K, Suzaki K. Effect of priming time on tensile bond strength to bovine teeth and morphologic structure of interfaces created by self-etching primers. Int J Prosthodont 2001;14(3):225-30.

15. Watanabe I, Nakabayashi N. Bonding durability of photocured Phenyl-P in TEGDMA to smear layer-retained bovine dentin. Quintessence Int 1993;24(5):335-42.

16. Barkmeier WW, Shaffer SE, Gwinnett AJ. Effects of 15 vs 60 second enamel acid conditioning on adhesion and morphology. Oper Dent 1986;11(3):111-16.

17. Perdigão J, Baratieri LN, Lopes M. Shear bond strengths of the newest one-bottle bonding systems. J Dent Res 1997;76:280.

18. Eventov VL, Andrianova MYu, Sepp NO, Korotkova OV. Use of information properties of biological liquids for correction of development of living organisms. Biomedical Engineering 2006;40:268-70.

19. Gonçalves SEP, Araujo MAM, Damião AJ. Dentin Bond strenght: Influence of laser irradiation, acid etching and hypermineralization. J Clin Med Surg 1999;17:77-859.

20. Gonçalves SEP, Crus N, Brayner R, Huhtala MFRL, Borges $\mathrm{AB}$, Barcellos DC. Grander system - a new technology to reduce surface tension of adhesive systems in dentistry 2011; No prelo.

21. Faissner K. Physical and physical-chemical data in the application of revitalized and nonrevitalized water and the use of Grander water revitalization in industry. March, 2000. [serial online] Available at: http://www.grander-tecnologie.com/en/ wissenschaft-forschung/DiplomarbeitUniGrass.php. Accessed may 26, 2011.

22. Toledano M, Osorio R, de Leonardi G, Rosales-Leal JI, Ceballos L, Cabrerizo-Vilchez MA. Influence of self-etching primer on the resin adhesion to enamel and dentin. Am J Dent 2001;14: 205-10.
23. Oh WS, Shen C, Alegre B, Anusavice KJ. Wetting characteristic of ceramic to water and adhesive resin. J Prosthet Dent 2002; 88(6):616-21.

\section{ABOUT THE AUTHORS}

\section{Sérgio Eduardo de Paiva Gonçalves}

Associate Professor, Department of Restorative Dentistry, São José dos Campos School of Dentistry, UNESP-São Paulo State University São Paulo, Brazil

\section{Diogo Toledo Matias}

Research Academic Group, São José dos Campos School of Dentistry UNESP-São Paulo State University, São Paulo, Brazil

\section{Daphne Câmara Barcellos}

Postgraduate Student, Department of Restorative Dentistry, São José dos Campos School of Dentistry, UNESP-São Paulo State University São Paulo, Brazil

\section{Maria Filomena Rocha Lima Huhtala}

Assistant Professor, Department of Restorative Dentistry, São José dos Campos School of Dentistry, UNESP-São Paulo State University São Paulo, Brazil

\section{Tânia Mara da Silva}

Postgraduate Student, Department of Restorative Dentistry, São José dos Campos School of Dentistry, UNESP-São Paulo State University São Paulo, Brazil

\section{Ivan Balducci}

Professor of Bioestatistic, Department of Social Odontology, São José dos Campos School of Dentistry, UNESP-São Paulo State University São Paulo, Brazil

\section{Carlos Rocha Gomes Torres}

Assistant Professor, Department of Restorative Dentistry, São José dos Campos School of Dentistry, UNESP-São Paulo State University São Paulo, Brazil

\section{CORRESPONDING AUTHOR}

Carlos Rocha Gomes Torres, Assistant Professor, Department of Restorative Dentistry, Avenida Engenheiro Francisco José Longo 777 Jardim São Dimas, São José dos Campos, CEP: 12245-000, São Paulo Brazil, Phone: (12) 3947 9048, Fax: (12) 39479010 e-mail: carlosrgt@fosjc. unesp.br 